УДК 330

\title{
ОБРАЗОВАНИЕ И СОВРЕМЕННЫЕ ВЫЗОВЫ ИНФОРМАЦИОННОГО ОБЩЕСТВА
}

\begin{abstract}
Выжигин Александр Юрьевич кандидат технических наук, доцент, заведующий кафедрой Жук Игорь Александрович кандидат экономических наук, доцент Резниченко Александр Васильевич кандидат технических наук, профессор Российская академия народного хозяйства и государственной службы при Президенте Российской Федерации
\end{abstract}

Аннотация: в работе в контексте информатизации общественной среды на основе массовой компьютеризации, развитии и внедрения новых информационных технологий рассмотрена идея новой парадигмы высшего образования - инновационного образования. В рамках этой концепции сформулированы основные компетенции образованного человека XXI века, формирование которых обеспечит необходимый человеческий ресурс для поступательного экономического развития государства.

Подчеркнуто, что цифровизация экономики невозможна без цифровизации системы образования, направленной на становления информационного общества в России, формирующего, в свою очередь, дополнительные информационно-технологические требования к интеллекту каждого гражданина.

В этой связи высказано предположение о необходимости трансформации акмеологии в цифровую акмеологию - синергетическую науку о закономерностях достижения максимального совершенства индивидуума посредством самоактуализации и развития компетенций в области информационных технологий, искусственного интеллекта, компьютерного моделирования и работы с «большими данными». Сформулированы понятия объекта и предмета исследования цифровой акмеологии. В качестве иллюстрации объективной потребности подобных изменений указаны рассмотренные на проходившем в Москве январе 2019 г. юбилейном «Гайдаровском» форуме в РАНХиГС при президенте РФ проблемы 
современного образования и пути их решения. Аналогичные подходы сформулированы и в Указе Президента Российской Федерации "О развитии искусственного интеллекта в Российской Федерации"

Предложен подход к созданию информационно-технологической модели обучения в вузе с использованием элементов искусственного интеллекта. Определены составные части модели (этапы обучения) и требования к их содержанию (компетенции лиц, реализующих эти этапы). На конкретном примере продемонстрирована работа модели, реализованной с применением программного пакета iSpring: интерфейс информационноконтрольного и тестового фреймов, таблицы самооценки и оценки обучаемого, анализ динамики усвоения знаний студентом.

Ключевые слова: Информационное общество, инновационное образование, цифровизация, цифровая акмеология, информационные технологии и элементы искусственного интеллекта, модель обучения.

\title{
EDUCATION AND MODERN CHALLENGES OF THE INFORMATION SOCIETY
}

\section{Vyzhigin Alexander Yurievich Zhuk Igor Alexandrovich Reznichenko Aleksandr Vasilievich}

\begin{abstract}
In the context of Informatization of the public environment on the basis of mass computerization, development and introduction of new information technologies, the idea of a new paradigm of higher education - innovative education is considered. Within the framework of this concept, the main competences of the educated person of the XXI century are formulated, the formation of which will provide the necessary human resource for the progressive economic development of the state.

It is emphasized that the digitalization of the economy is impossible without the digitalization of the education system aimed at the formation of the information society in Russia, which, in turn, forms additional information and technological requirements for the intelligence of every citizen.

In this regard, the author suggests the need to transform acmeology into digital acmeology - a synergistic science about the laws of achieving maximum perfection of the individual through self-actualization and development of 306
\end{abstract}


competencies in the field of information technology, artificial intelligence, computer modeling and work with "big data". The concepts of the object and subject of digital acmeology research are formulated. As an illustration of the objective need for such changes are listed considered at the held in Moscow in January 2019 the anniversary "Gaidar" forum in Ranepa under the President of the Russian Federation problems of modern education and their solutions. Similar approaches are formulated in the Decree of the President of the Russian Federation "on the development of artificial intelligence in the Russian Federation".

An approach to the creation of information technology model of education at the University using elements of artificial intelligence is proposed. The components of the model (stages of training) and the requirements for their content (competence of persons implementing these stages) are defined. The work of the model implemented with the use of the iSpring software package is demonstrated on a specific example: the interface of the information control and test frames, the tables of self-assessment and evaluation of the student, the analysis of the dynamics of knowledge acquisition by the student).

Key words: Information society, innovative education, digitalization, digital acmeology, information technologies and elements of artificial intelligence, learning model.

Информатизация общества рассматривается в настоящее время как один из важнейших процессов, характерных для мирового сообщества и нашей страны. Однако информатизация - это не только социотехнический или даже социотехнологический процесс, или явление, но и устойчивая тенденция социального развития, необходимость которого доказана теорией и практикой.

Наиболее общее системно-деятельностное определение процесса информатизации дано А.Д. Урсулом [1]: информатизация представляет собой интеллектуально-гуманистическую перестройку всей жизнедеятельности человека и общества на основе нее более полного использования с помощью средств информатики информачии как ресурса развития, новых информачионных технологий с целью создания информационного общества и дальнейшего становления ноосферы.

Вот почему основная тенденция развития современного мира представляет собой переход человечества $\kappa$ постиндустриальной, технологической, информационной эпохе своего развития, в которой важнейшую роль играют не столько научные знания, описывающие мир, 307 


\section{СОВРЕМЕННОЕ СОСТОЯНИЕ И ПЕРСПЕКТИВЫ РАЗВИТИЯ СОВРЕМЕННОЙ НАУКИ И ОБРАЗОВАНИЯ}

сколько технологии его преобразования. А информационному обществу, в котором "информация и уровень ее применения и доступности кардинальным образом влияют на экономические и социокультурные условия жизни граждан", необходима и инновационная экономика - экономика, основанная на знаниях, новых технологиях с применением искусственного интеллекта и человеческом капитале [2].

Основой прогрессивного развития экономики каждой страны и всего человечества в целом является сам человек, от которого требуются не только профессиональные знания, умения, исполнительность и дисциплина, на первый план выходят его акмеология - духовно-нравственные качества и культура, творческий потенциал и профессиональная компетентность, вершина развития, наибольшего расцвета человеческой личности $[3,4]$. Именно поэтому целью стратегии развития информационного общества в Российской Федерации на 2017 - 2030 годы является обеспечение развитие человеческого потенциала.

Таким образом, в современном обществе возникла и активно развивается идея новой парадигмы высшего образования - концепции инновационного образования (по терминологии экспертов Римского клуба).

В рамках этой концепции для образованного человека XXI века необходимо обладание следующими основными компетенциями [5]: общение на родном языке; общение на иностранных языках; математические способности и основные компетенции (умения) в науке и технологии; информационная компетентность; умение учиться в режиме самоактуализации и саморазвития.

Считается к окончанию школы (начальное образование) у молодых людей эти основные компетенции должны быть развиты до уровня, достаточного для взрослой жизни, чтобы затем сохраняться, развиваться и модернизироваться в соответствии с динамикой развития общественных отношений. То есть, необходимость постоянного освоения всех компетенций в современном обществе выдвигает образование на роль главного ресурса общественного прогресса, подлинного капитала каждого человека и человечества в целом.

Вот почему образование рассматривается как ресурс для поступательного экономического развития и средство обеспечения превосходства страны в случае, если в сфере высшего образования будут адекватно реализованы те же характеристики, которые являются 308 


\section{СОВРЕМЕННОЕ СОСТОЯНИЕ И ПЕРСПЕКТИВЫ РАЗВИТИЯ СОВРЕМЕННОЙ НАУКИ И ОБРАЗОВАНИЯ}

определяющими для современной инновационной экономики, постиндустриальной и информационной цивилизации.

К этим характеристикам относятся [6]:

- гибкость и нелинейность организационных форм производства и социальной сферы;

- включение процессов получения и обновления знания во все производственные и общественные процессы;

- опора на талант, креативность и инициативность человека как на важнейший ресурс экономического и социального развития;

- многократные изменения технологий (в том числе и социальных) за короткие промежутки времени и т.д.

Таким образом инновационное образование должно основываться на интеграции наиболее современных и эффективных технологий образования с интенсивной научно-исследовательской деятельностью; на связи вузовских исследований, проводимых на переднем крае науки и техники, с потребностями общества в целом и экономики в частности; на междисциплинарности образования.

Вот почему Президент Российской Федерации В.В. Путин в своем послании Федеральному Собранию РФ от 20 февраля 2019 года определил в качестве основных приоритетов не только "... опережающий темп роста производительности труда, прежде всего на основе новых технологий и цифровизации ...", но и "... подготовку современных кадров, создание мощной научно-технологи-ческой базы".

Однако цифровизация экономики - это не просто перевод данных и процессов из «аналоговой» эпохи в цифровой вид. А цифровизация системы образования не может ограничиться созданием цифровой копии привычных учебников, оцифровкой документооборота и предоставлением школам всеобъемлющего доступа к Интернету как средству достижения "цифровой грамотности".

Под цифровой грамотностью следует понимать набор знаний, умений и навыков, которые необходимы для жизни в современном мире, для безопасного и эффективного использования цифровых технологий и ресурсов Интернета. Вот почему цифровая грамотность - это способность создавать и использовать контент с помощью цифровых технологий, включающих работу с информационными и экспертными системами, системами 


\section{СОВРЕМЕННОЕ СОСТОЯНИЕ И ПЕРСПЕКТИВЫ РАЗВИТИЯ СОВРЕМЕННОЙ НАУКИ И ОБРАЗОВАНИЯ}

искусственного интеллекта; работу с большими объемами данных («большими данными»); навыки компьютерного моделирования; коммуникацию с другими людьми с применением информационных технологий и т.п.

Развитие цивилизации происходит в направлении становления информационного общества, в котором объектами и результатами труда большинства занятого населения будут не материальные ценности, а главным образом информация и научные знания, что формирует дополнительные информационно-технологические требования к интеллекту каждого гражданина.

В этой связи акмеология как наука, изучающая закономерности и механизмы развития человека по ступеням его зрелости и особенно при достижении им наиболее высокого уровня в этом развитии, также должна претерпеть, на наш взгляд, значительные изменения, трансформируясь в цифровую акмеологию - синергетическую науку о закономерностях достижения максимального совершенства индивидуума посредством самоактуализации и развития компетенций в области информационных технологий, искусственного интеллекта, компьютерного моделирования и работы с «большими данными».

Объектом исследования цифровой акмеологии должна стать цифровая экономика и цифровое общество в целом - среда, в условиях которой и реализуется достижение максимально возможного уровня совершенства человека.

Предметом исследования цифровой акмеологии - построение индивидуальной траектории обучения человека по развитию навыков самоактуализации (самоорганизации) в условиях цифрового общества с применением информационных технологий и искусственного интеллекта.

В педагогической интерпретации акмеология является наукой, изучающей развитие человека на ступени взрослости и достижения им вершины в этом развитии как природного существа (индивида), как личности и как субъекта деятельности (главным образом как профессионала).

Возникнув как новая парадигма на стыке наук общественных, технических, гуманитарных и естественных акмеология решает задачи выявления оптимальных факторов и условий, которые позволяют взрослому человеку состояться как индивиду, личности и субъекту деятельности, т.е. достичь своего «акме» (прежде всего в профессиональной деятельности). 


\section{СОВРЕМЕННОЕ СОСТОЯНИЕ И ПЕРСПЕКТИВЫ РАЗВИТИЯ СОВРЕМЕННОЙ НАУКИ И ОБРАЗОВАНИЯ}

Реализация этого подхода в общей концепции совершенствования системы образования XXI века является, на наш взгляд, определяющим и требует решения ряда общепризнанных задач.

Реализация этого подхода в общей концепции совершенствования системы образования XXI века является, на наш взгляд, определяющим и требует решения ряда общепризнанных задач.

Так на проходившем в Москве январе 2019 г. юбилейном «Гайдаровском» форуме в РАНХиГС при президенте РФ Министр высшего образования, исследований и инноваций Французской Республики Фредерик Видаль отметила особую роль объединения гуманитарных наук и естественнонаучного знания в цифровую эпоху, необходимость внедрения проектного метода обучения и междисциплинарного образования, указала на нехватку квалифицированных кадров, которые могут адаптироваться к меняющемуся миру, как часть актуальных рисков международного развития и назвала насущной необходимостью трансформацию всей системы образования с применением современных информационных технологий в целом и методов искусственного интеллекта в частности.

Использование технологий искусственного интеллекта значительной степени способствует повышению качества услуг в сфере образования путем адаптации образовательного процесса к потребностям обучающихся и потребностям рынка труда, системного анализа показателей эффективности обучения для оптимизации профессиональной ориентации и раннего выявления детей с выдающимися способностями, автоматизации оценки качества знаний и анализа информации о результатах обучения.

Исходя из выше сказанного, предлагается следующая модель обучения в ВУЗе в эпоху цифровой экономики (рис. 1).

\section{1. Блок отбора учебного материала}

Для отбора учебного материала привлекаются эксперты, обладающие компетенциями, представленными выше, а также преподаватели, читающие курс. Методы их работы при этом могут быть самыми разнообразными, включая метод анализа иерархий [5] для определения степени информативности, простоты усвоения и взаимосвязи текстуальных, графических и аналитических составляющих учебного контента. 
Модель обучения в ВУЗе эпоху в цифровой экономики

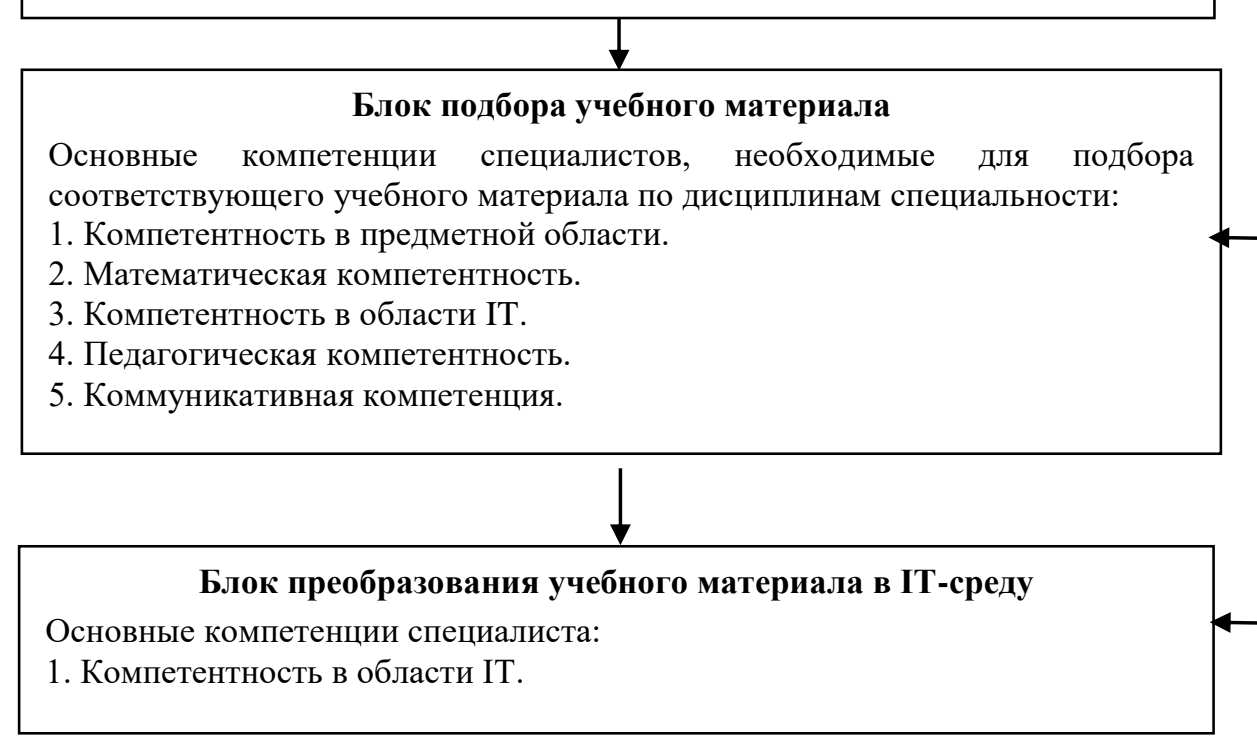

\begin{tabular}{|c|}
\hline Блок обучения \\
\hline $\begin{array}{l}\text { IT-среда } \\
\text { 1. Наличие компьютера, планшета, смартфона. } \\
\text { 2. Наличие интернет-ресурса, образовательного контента по специальности } \\
\text { ВВУЗа на едином сертифицированном компьютерном программном } \\
\text { обеспечении. } \\
\text { 3. Наличие связи "студент-преподаватель-студент", позволяющей построить } \\
\text { с использованием средств (элементов) искуственного интеллекта } \\
\text { индивидуальную траекторию обучения каждого студента }\end{array}$ \\
\hline $\begin{array}{l}\text { Блок студента } \\
\text { Основные компетенции студента: } \\
\text { 1. Умение учиться. } \\
\text { 2. Компетентность в области IT. }\end{array}$ \\
\hline 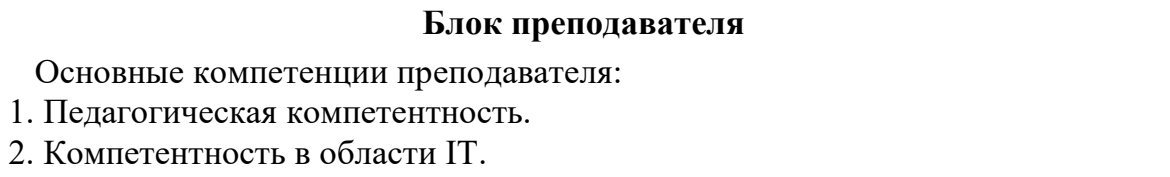 \\
\hline
\end{tabular}

Рис. 1. Модель обучения в ВУЗе в эпоху цифровой экономики

\section{2. Блок конвертации учебного материала в IT среду.}

Специалисты, конвертирующие отобранный экспертами и преподавателями учебный материал в электронный продукт, применяют самые различные IT технологии.

В качестве современных программных продуктов, которые позволяют 
создавать преподавателям электронные средства обучения, следует отметить: Articulate Storyline; Moodle; Docebo; Geenio. Анализ возможностей этих пакетов программ [7] позволил выделить iSpring в качестве наиболее эффективного, для реализации предлагаемой модели обучения.

Результатом конвертации учебного контента с помощью пакета $i$ Spring является система фреймов сложной структуры, где представлены информационный блок: текст, графические и мультимедийные объекты (рисунки, аудио и видео материалы), математические зависимости, а также элементы управления работой с фреймом (рис. 2, 3).

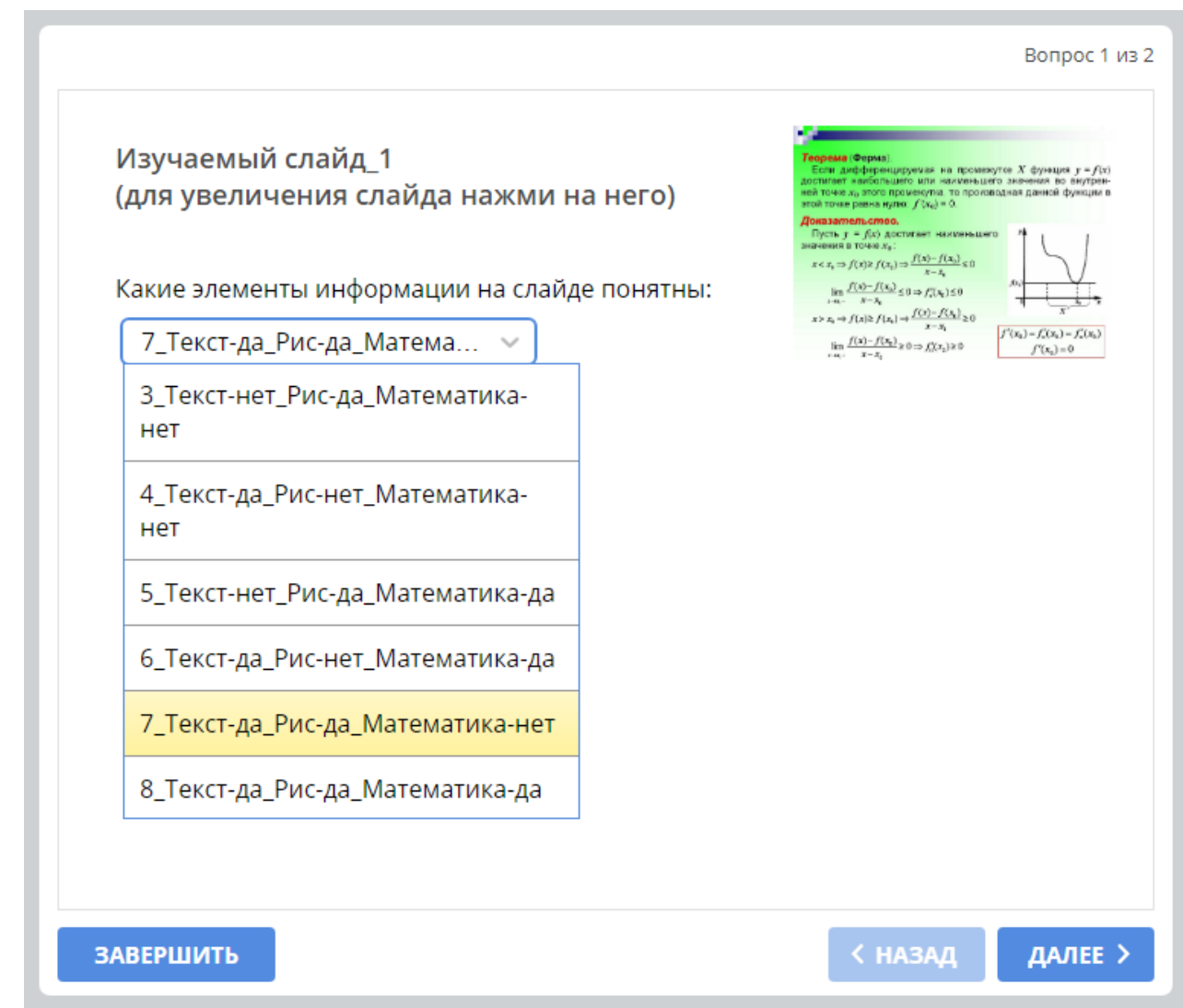

Рис. 2. Интерфейс информационно-контрольного фрейма в пакете iSpring 


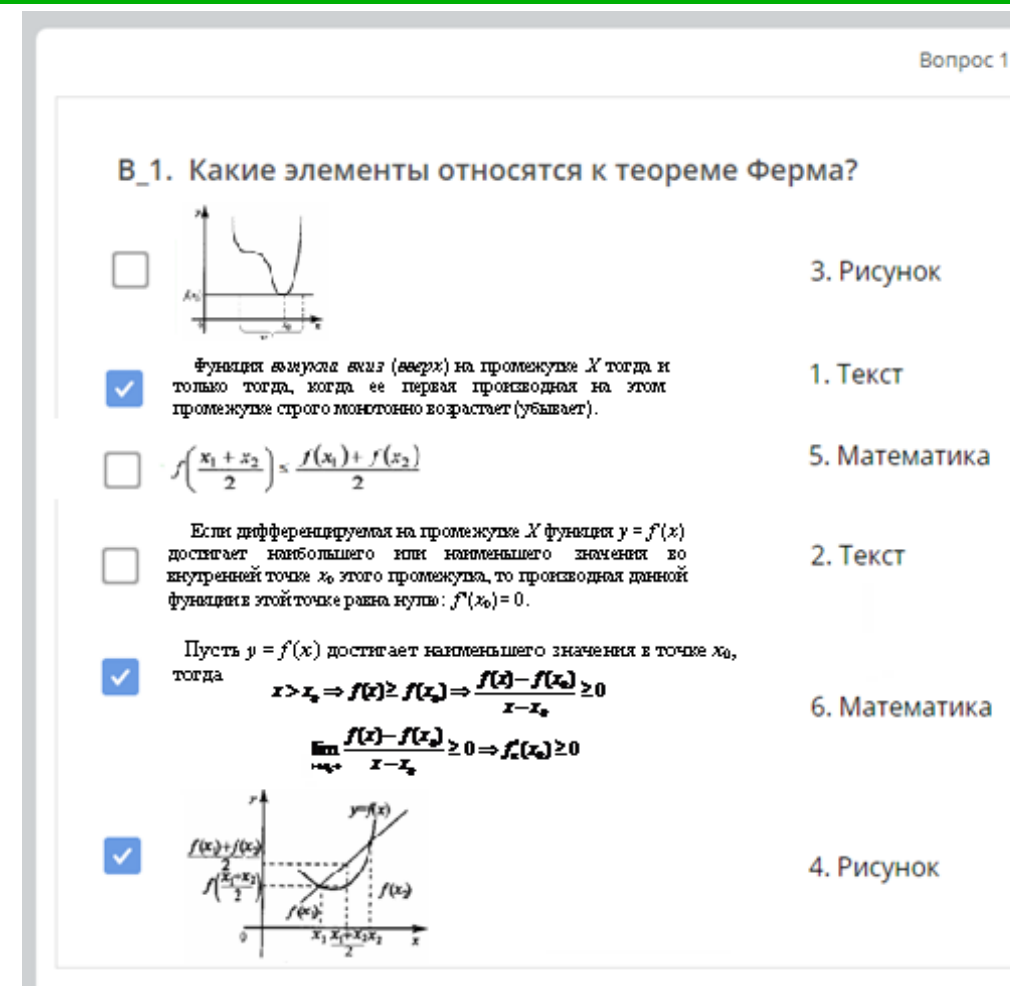

\section{ОТВетИть}

\section{Рис. 3. Интерфейс тестового фрейма в пакете iSpring}

Помимо традиционных элементов навигации ("Назад", "Далее", "Завершить"), студенту предоставлена возможность варьировать для удобства работы размер информационного поля.

По завершению работы с фреймом студенту предоставляется возможность охарактеризовать степень уяснения (восприятия) материалов информационного блока для чего необходимо воспользоваться шкалой бинарных оценок, реализованной на фрейме в виде раскрывающегося списка. Данная информация, а также время работы с материалом будут автоматически переданы преподавателю для последующего контроля обучаемого и организации ему необходимой помощи (осуществления обратной связи).

Помимо информационно-контрольных фреймов предполагается создание и тестовых по каждому информационному блоку. При формировании теста (рис. 3) ІТ-специалист опирается на мнение преподавателя о конкретном контенте информационного блока лекционного фрейма, подлежащем проверке, и виде теста (бинарный выбор, выбор "один из многих", множественный выбор и др.). Полученные результаты агрегируются преподавателем в результат за весь лекционный материал.

Информационно-технологические аспекты сбора, агрегирования и 314 


\section{СОВРЕМЕННОЕ СОСТОЯНИЕ И ПЕРСПЕКТИВЫ РАЗВИТИЯ

структурирования информации об обучении по модели будут рассмотрены в блоке преподавателя.

\section{3. Блок студента.}

Работа студента с учебным материалом предполагает наличие IT-среды, а сам обучаемый должен обладать перечисленными выше компетенциями.

Поскольку предлагаемы программный продукт обладает элементами обратной связи, то любое обращение к нему начинается с идентификации обучаемого и выбора индивидуального средства работы и связи, поскольку программный пакет iSpring допускает вариативность оконечных устройств (компьютер, планшет, смартфон). Дальнейший порядок и технология работы студента с программным пакетом стандартно определяется интерфейсом фрейма и включает: работу с материалом, уяснение его содержания по типам информации, самостоятельная оценка ("понял- не понял" и что именно рисунок 2), прохождение теста и дальнейшее движение по траектории изучения лекционного материала.

Идентификация обучаемого дает возможность преподавателю не только собрать и обобщить данные о степени уяснения материалов информационного блока (самооценка обучаемого) и теста (объективная оценка его знаний), но и связать их сравнительный анализ с конкретным студентом для формирования ему индивидуальной траектории изучения материалов лекции.

Еще одним преимуществом применения настоящей программной продукции является ее инвариантность относительно используемых студентами технических средств, что обеспечивает не только режим самообучения (саморазвития) студента, но и позволяет проведение лекций в любых необорудованных мультимедийными средствами аудиториях или удаленно. Единственное требование - наличие Интернета.

\section{4. Блок преподавателя.}

Работа преподавателя с учебным материалом так же безусловно предполагает наличие IT-среды и обладание компетенциями в предметной области, а так же и области Internet-технологий. Последнее необходимо для обработки присылаемых обучаемыми файлов и предполагает умением работать с почтовыми сообщениями и знание программ MS Office.

Первым этапом работы является сбор и обработка информации о выполненных обучаемыми заданиях (самостоятельная оценка), которая в автоматическом режиме поступает на почту преподавателя в формализованном виде. 
В предыдущей версии пакета iSpring для обработки данных было необходимо поместить текст сообщения в txt-файл для последующего переноса в базу данных, сформированную в виде Excel-файла [7]. Перенос осуществлялся с помощью разработанной авторами (Жук И.А.) программы на VBA. В современной версии пакета iSpring эта процедура разработчиками фирмы усовершенствована: текст почтового сообщения уже имеет Excelформализацию и не требует использования промежуточных файлов для переноса в базу данных. Однако сам перенос так же осуществляется с помощью специально разработанного макроса, содержание которого не приводится вследствие ограниченности размеров статьи.

При реализации макроса автоматически выполняется процедура идентификации (присвоения кода) степени уяснения обучаемым материалов лекции в соответствии с его ответами на информационно-контрольной фрейме. Шкала идентификации степени уяснения обучаемым материалов лекции представлена на рис. 4.

\begin{tabular}{|c|c|c|c|}
\hline Код & Текст & Рисунок & Математика \\
\hline 1 & $0-$ Нет & $0-$ Нет & $0-$ Нет \\
\hline 2 & $0-$ Нет & $0-$ Нет & $1-$ Да \\
\hline 3 & $0-$ Нет & $1-$ Да & $0-$ Нет \\
\hline 4 & $1-$ Да & $0-$ Нет & $0-$ Нет \\
\hline 5 & $0-$ Нет & $1-$ Да & $1-$ Да \\
\hline 6 & $1-$ Да & $0-$ Нет & $1-$ Да \\
\hline 7 & $1-$ Да & $1-$ Да & $0-$ Нет \\
\hline 8 & $1-$ Да & $1-$ Да & $1-$ Да \\
\hline
\end{tabular}

\section{Рис. 4. Шкала идентификации}

Формализованная таким образом информация по самооценке обучаемого помещается в "умную таблицу" (рис. 5), использующую когнитивную графику для акцентирования внимания преподавателя на предполагаемом уровне его подготовленности.

\begin{tabular}{|c|c|c|c|c|c|c|c|c|c|c|}
\hline A & & B & C & D & $\mathrm{E}$ & $\mathrm{F}$ & G & $\mathrm{H}$ & 1 & J \\
\hline Фамилия & $\nabla$ & Имя & Отчество & - Год & Месяц $\mathbf{v}$ & День месяца $\mathbf{v}$ & Лекция № & Время на лекцию(мин) & 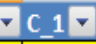 & C. 2 V \\
\hline Сидоров & & Семен & Семенович & 2019 & январь & 12 & 1 & 50 & 7 & 8 \\
\hline Сидоров & & Семен & Семенович & 2019 & январь & 15 & 1 & 50 & 8 & 8 \\
\hline Сидоров & & Семен & Семенович & 2019 & январь & 20 & 1 & 50 & 8 & 8 \\
\hline Сидоров & & Семен & Семенович & 2019 & январь & 25 & 1 & 50 & 8 & 8 \\
\hline Сидоров & & Семен & Семенович & 2019 & февраль & 8 & 1 & 50 & 8 & 8 \\
\hline Сидоров & & Семен & Семенович & 2019 & февраль & 27 & 1 & 50 & 8 & 8 \\
\hline Сидоров & & Семен & Семенович & 2019 & март & 11 & 1 & 50 & 8 & 8 \\
\hline Сидоров & & Семен & Семенович & 2019 & март & 15 & 1 & 50 & 8 & 8 \\
\hline
\end{tabular}

Рис. 5. Таблица самооценки обучаемого 


\section{СОВРЕМЕННОЕ СОСТОЯНИЕ И ПЕРСПЕКТИВЫ РАЗВИТИЯ

Проанализировав в "умной таблице" MS Excel результаты самооценки работы обучаемого с лекцией (в статье рассмотрен пример одного фрейма), преподаватель для каждого студента или для группы студентов формирует индивидуальную траекторию ее изучения. Последующие результаты освоения материала с учетом предложений преподавателя по индивидуальному плану работы так же заносятся в таблицу для визуализации динамики процесса обучения.

Наличие в таблице временных показателей работы с материалом позволяют оценить истинное прилежание обучаемого.

Второй этап работы преподавателя заключается в сборе и обработке информации о тестовых испытаний обучаемых по материалам темы курса, которая может включать несколько лекций.

Материалы теста формируются из общей базы "вопросов-ответов", объединяющей три раздела: текст, рисунок, математика. Выбор конкретных вопросов теста определяется содержанием и структурой фрейма, а также вида теста (бинарный выбор, выбор "один из многих", множественный выбор и др.). Чередование объектов в окне фрейма (правильных и неправильных ответов по разделам) - случайное.

Данные теста также в автоматическом режиме поступает на почту преподавателя в формализованном виде.

Excel-структурированные почтовые данные теста обучаемого аналогично копируются в файл с макросом и переносятся в умную таблицу (рисунок 6). Шкала идентификации степени правильности ответов студента на вопросы теста аналогична представленной на рис. 6.

Отличием контента результатов теста (на почте или в Excel-файле) от данных самооценки обучаемого заключается развернутом указании преподавателя на правильность или неправильность каждого ответа студента на все вопросы (с указанием правильного решения).

Содержанием третьего этапа работы преподавателя является сравнительный анализ данных самооценки обучаемого и объективных результатов теста для принятия решений по совершенствованию учебного процесса.

\begin{tabular}{|c|c|c|c|c|c|c|c|c|c|}
\hline A & B & $\mathrm{C}$ & D & $E$ & $\mathrm{~F}$ & G & H & 1 & J \\
\hline Фамилия & $\checkmark$ Имя & Отчество & च Год & Месяц $\mathrm{V}$ & День месяца & Тест поЛекция & Время на тест(мин) & $\nabla C_{1} 1 \mathrm{~V}$ & C $22 \mathrm{v}$ \\
\hline Сидоров & Семен & Семенович & 2019 & январь & 27 & 1 & 2 & 2 & 7 \\
\hline Сидоров & Семен & Семенович & 2019 & февраль & 15 & 1 & 2 & 7 & 7 \\
\hline Сидоров & Семен & Семенович & 2019 & март & 20 & 1 & 2 & 6 & 5 \\
\hline
\end{tabular}

Рис. 6. Таблица оценки обучаемого по результатам теста 
Так данные "умной таблицы" результатов проверки знаний обучаемого показывают, что в режиме тестирования фрейм лекционного материала «1» (слайд_1) усвоен с кодом «2», что существенно разнится с самооценкой студента за январь (код «7»). Преподавателю необходимо обратить на это внимание и предложить обучаемому материалы для дополнительного изучения вопроса.

Особенно наглядна динамика процесса сравнения на гистограмме (рис. 7) по лекционному фрейму «1» (слайд_1) лекции_1, где первоначальный рост степени усвоения материала завершается его спадом при той же завышенной самооценке.

Снижение уровня знаний студента, по объективной оценке (тест), при сохранении этого уровня по самооценке, может быть связано с часто практикуемым в студенческой среде механическим запоминанием материала, приводящем к формальному усвоению знаний путем последовательного заучивания отдельных частей материала без опоры на смысловую связь между ними.

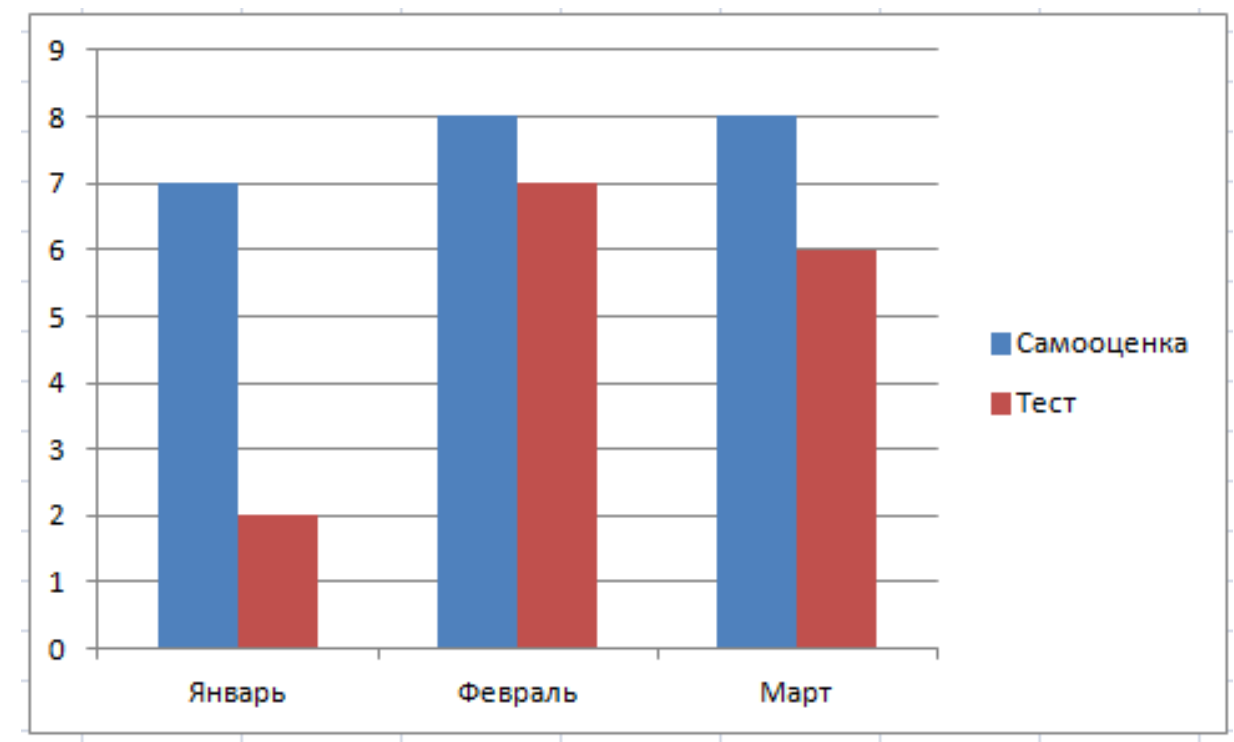

Рис. 7. Пример динамики оценки и самооценки знаний обучаемого (слайд_1)

Смысловое же запоминание основано ни понимании смысла, осознании отношений и внутренней логической связи как между частями запоминаемого материала, так и между данным материалом и прежними знаниями, что составляет, на наш взгляд, основу акмеологического подхода в педагогике, ориентированного на целостное и устойчивое развитие субъектов 318 


\section{СОВРЕМЕННОЕ СОСТОЯНИЕ И ПЕРСПЕКТИВЫ РАЗВИТИЯ СОВРЕМЕННОЙ НАУКИ И ОБРАЗОВАНИЯ}

образовательного процесса. Применение же современных IT-технологий для повышения эффективности обучения в ВУЗе в контексте цифровизации системы образования и базируется не столько на достижении всеобщей цифровой грамотности, а на смысловом подходе к усвоению знаний.

Таким образом информационно-технологический подход авторов к организации и контролю обучения хотя и не обеспечивает, безусловно, трансформацию всей системы образования с применением современных информационных технологий, но те не менее предлагает способ индивидуализации и интенсификации образовательного процесса путем перехода к применению элементов теории искусственного интеллекта ("умной таблицы") в целях обеспечения качественной подготовки квалифицированных кадров XXI века.

В заключение необходимо отметить, что с развитием и расширением использования образовательных информационных технологий связываются надежды на повышение эффективности обучения. По мнению экспертов, новые информационные технологии обучения позволяют повысить эффективность практических занятий не менее чем на $30 \%$, объективность контроля знаний учащихся - на 20-25\% [8]. При этом необходимо подчеркнуть, что оценка эффективности методов обучения с применением информационных технологий в сравнении с методами модели традиционного образования ограничивается обычно лишь измерением результата обучения, а иногда и затрат времени учащихся. На самом же деле внедрение информационных технологий влияет на качество и содержание образования, например, позволяют проводить занятия с использованием компьютерных моделей, имитирующих функционирование сложных процессов, практическая реализация которых недоступна учебным заведениям.

\section{Список литературы}

1. Урсул, А.Д. Информатизация общества (Введение в социальную информатику): учебное пособие / Урсул А.Д. - Москва: Академия общественных наук, 1990. - 191с.

2. Лызь Н.А., Лызь А.Е. Тенденции развития высшего образования. Учебно-методическое пособие / Н.А. Лызь, А.Е. Лызь - Таганрог: Изд. "Технологический институт Южного федерального университета", 2012.- 47c.

3. Манушин, Э.А. Проблемы и перспективы инновационного развития российского высшего образования / Э.А. Манушин - Москва: Изд-во 
"Российское академическое образование", Информационное, педагогическое, научно-методическое издание "Профессиональное образование. Столица", № 4, 2013. - c. 10-13.

4. Резниченко, А.В. Человек и образование в современном информационно-техногенном мире: монография / А.В. Резниченко. - Москва: OBA ВC РФ, 2004. - 112 c.

5. Жук И.А., Резниченко А.В. Оценка эффективности образовательного процесса с применением метода анализа иерархий // Международная конференц-сессия «Государственное управление и развитие России: вызовы и возможности» (Москва, ИГСУ РАНХиГС, 14 -18 мая 2018) - М.: Изд. дом "НАУЧНАЯ БИБЛИОТЕКА", 2018. - Т.1, с. 869 - 884.

6. Кузьминов Я.И. и др. Российское образование - 2020: модель образования для инновационной экономики / Я.И. Кузьминов. - М.: Изд. дом "Высшая школа экономики", академический журнал "Вопросы образования", №1, 2008. - с. 38-39.

7. Жук И.А., Резниченко А.В. Особенности формирования и использования лекционного материала с применением современных информационных технологий // Международная конференц-сессия «Государственное управление и развитие России: выбор приоритетов» (Москва, ИГСУ РАНХиГС, 16 -19 мая 2017) - М.: Изд-во ООО "Проспект", 2017. - T.1, c. $194-205$.

8. Образование и 21 век: Информационные и коммуникационные технологии / Под ред. В.Г. Кинелева. - Москва: Наука, 1999. - 264 с. 